\title{
Electron Density Comparison Between IRI 2007 and DEMETER Satellite Data in Solar Minimum Year
}

\author{
Xuemin Zhang* \\ Institute of Earthquake Science, China Earthquake Administration, Beijing, China.
}

Received 22 October 2013, revised 13 February 2014, accepted 24 February 2014

\begin{abstract}
Solar activity during 2008 - 2009 was extremely low among several recent solar cycles, raising an interesting question regarding the temporal and spatial distribution of the plasma parameters in ionosphere during this time period. This study analyzes the electron density $\left(\mathrm{N}_{\mathrm{e}}\right)$ data recorded by the DEMETER satellite at the height of $670 \mathrm{~km}$ and compares it with the International Reference Ionosphere (IRI) 2007 model with special emphasis on the solar minimum year of 2008. The results show that in local nighttime around 22:30 the global distribution of $\mathrm{N}_{\mathrm{e}}$ by the DEMETER satellite exhibited similar behavior as that by IRI model, but $\mathrm{N}_{\mathrm{e}}$ is overestimated above $100 \%$ by the IRI in equatorial and beyond geomagnetic latitudes of $50^{\circ}$, while underestimated by $-70 \%$ at $20^{\circ}-40^{\circ}$ in the north or south hemisphere during different seasons. In local daytime around $10: 30, \mathrm{~N}_{\mathrm{e}}$ values are mostly overestimated by the IRI model especially in the equatorial area where double crests were exhibited clearly at $\pm 10^{\circ}$ in the IRI-N $\mathrm{N}_{\mathrm{e}}$ Quick model, but only one crest around $0^{\circ}-10^{\circ} \mathrm{N}$ shown by DEMETER. Combined with other satellite data double crests of $\mathrm{N}_{\mathrm{e}}$ over the equatorial area may gradually evolve into a single peak near LT 10:30 at $600 \mathrm{~km}$ height. The DEMETER comparison with three options in IRI 2007 revealed that only the IRI-2001 option gave a single crest as with DEMETER, and three IRI options all largely overestimated the crest $\mathrm{N}_{\mathrm{e}}$ values from DEMETER in local daytime. The results in this paper provide new information for improving the IRI model in the future, helping to understand the ionosphere and upper atmosphere physics, with applications in communications, navigation and spacecraft orbit determination.
\end{abstract}

Key words: Electron density, IRI model, Solar minimum, DEMETER satellite

Citation: Zhang, X., 2014: Electron density comparison between IRI 2007 and DEMETER satellite data in solar minimum year. Terr. Atmos. Ocean. Sci., 25, 559-571, doi: 10.3319/TAO.2014.02.24.01(AA)

\section{INTRODUCTION}

The spatial-temporal variation of plasma parameters in the ionosphere during the deep solar minimum for the years 2008 - 2009 has become a critical issue in various space physics fields such as the solar-heliospheric-geospace system, the ionosphere and upper atmosphere physics, the solar EUV intensity on thermosphere cooling simulation and the predictive ability of the current IRI model (Gibson et al. 2009; Heelis et al. 2009; Lühr and Xiong 2010; Emmert et al. 2010; Russell et al. 2010; Solomon et al. 2010; AraujoPradere et al. 2011; Chen et al. 2011; Liu et al. 2011a, b, c, 2012). As we all know the IRI model has been widely used to provide electron density profiles and other plasma parameters for telecommunications, satellite navigation and positioning systems. When high frequency (HF) radio waves

\footnotetext{
* Corresponding author

E-mail: zhangxm96@126.com
}

propagate in the ionosphere they show different behaviors depending on their frequencies, electron oscillation frequency and ionospheric plasma refractive index (Ferguson and McNamara 1986; Oyinloye 1988; Maltseva et al.2007). An accurate model of the ionosphere and upper atmosphere is significantly important for spacecraft orbit determination and attitude control.

The solar activity during $2008-2009$ is a prolonged minimum among several recent solar cycles, thereby providing a unique opportunity to explore the ionospheric and thermospheric responses under this extreme condition (Lühr and Xiong 2010; Solomon et al. 2010; Tulasi Ram et al. 2010; Lei et al. 2011; Liu et al. 2011a, b, c; Cherniak et al. 2013; Zakharenkova et al. 2013). The solar cycle 23/24 minimum was quite special in its absence of sunspots for a number of days (Livingston and Penn 2009). The IRI model is a purely empirical model based on a large collection of satellites and 
ground-based observations (Bilitza 1992, 2003, 2004; Bilitza and Reinisch 2008), and it describes the monthly average conditions, not day-to-day variations, which should be considered in comparison with real observational data. An empirical model like the IRI has to rely on extrapolation to describe the ionosphere during the very low and prolonged minimum. It was found that the empirical ionospheric models overestimated the satellite observations of the upper transition height, the ion temperature and $\mathrm{N}_{\mathrm{e}}$ in the topside ionosphere (Lühr and Xiong 2010; Kakinami et al. 2011; Liu et al. 2011a, b, 2012). Lühr and Xiong (2010) showed that the International Reference Ionosphere (IRI) 2007 model (Bilitza and Reinisch 2008) overestimated the $\mathrm{N}_{\mathrm{e}}$ observations of CHAMP and GRACE satellites by 50\% in 2008 and more than $60 \%$ in 2009 , respectively. In contrast, the models reasonably predicted the satellite observations for other years. Some big deviations were revealed between the in-situ $\mathrm{N}_{e}$ detected by satellites at a certain altitude and $\mathrm{N}_{\mathrm{e}}$ by the IRI model, especially in equatorial areas with the equatorial ionization anomaly (EIA), such as CHAMP, GRACE, Hinotori, and DMSP (Watanabe et al. 1995; Bhuyan et al. 2003; Lei et al. 2007; Liu et al. 2007a; Kakinami et al. 2008; Lühr and Xiong 2010), while these satellite data have been contributing to improve the IRI model in turn. Due to these differences, new efforts are underway to improve the IRI model using C/NOFS, CHAMP and ionosonde data (Klenzing et al. 2011, 2013; Bilitza et al. 2012).

The main objective of this research is to analyze the observational results from the DEMETER satellite and investigate the differences from the IRI model. The DEMETER satellite operating time was from July 2004 to December 2010 , just at the descending phase of the $23^{\text {rd }}$ solar cycle. The electron density spatial-temporal features during the minimum solar activity of 2008 were mainly discussed and compared with the IRI model. In the meantime the satellite observations in 2005 have also been analyzed with the same methods, when the solar activity was in the declining phase, from the peak to the valley in the $23^{\text {rd }}$ solar cycle.

\section{DEMETER SATELLITE}

The Detection of Electro-Magnetic Emissions Transmitted from Earthquake Regions (DEMETER) satellite was launched on June 29, 2004 (Cussac et al. 2006), declination of $98.23^{\circ}$, and altitude of $710 \mathrm{~km}$ (which decreased to $670 \mathrm{~km}$ in mid December 2005). The scientific payloads on this microsatellite (Lagoutte et al. 2006) consist of: ICE - for the measurement of electric field, IMSC - for the measurement of magnetic field, IAP - a plasma analyzer, IDP - an energetic particle detector, and ISL - a set of two Langmuir probes to detect electron density and temperature. The satellite was designed for a sun-synchronous orbit, with down and up orbits crossing the equator at 10:30 and 22:30 LT respectively.

The specific scientific objectives of the DEMETER
Langmuir Probe Instrument (ISL: Instrument Sonde de Langmuir) are designed to map the bulk plasma parameters (primarily $\mathrm{N}_{\mathrm{e}}$ and electron temperature) and to study the variations associated with solid-earth events (e.g., earthquakes and volcanoes) and other sources of perturbations (Lebreton et al. 2006). The Langmuir probe installed on DEMETER sweeps $\pm 3.81 \mathrm{~V}$ in voltage. A complete voltage sweep is performed in $1 \mathrm{~s}$, to obtain the current-voltage (I-V) characteristic, in the spatial resolution of about $7 \mathrm{~km}$ at the altitude of $710(670) \mathrm{km}$. In this way the plasma parameters, including $\mathrm{N}_{\mathrm{e}}$, electron temperature $\left(\mathrm{T}_{\mathrm{e}}\right)$, ion density $\left(\mathrm{N}_{\mathrm{i}}\right)$ and spacecraft potential $\left(\mathrm{V}_{\mathrm{s}}\right)$ are obtained with 1s time resolution.

A graphical method was employed (Lebreton et al. 2006) for Langmuir probe I-V characteristic analysis which consists of approximating the three main regions of the I-V characteristic: the ion saturation region, the electron retardation region and the electron saturation region. This method works well when the plasma distribution follows a Maxwellian distribution and no photoelectrons or secondary particles are present, and when magnetic field effects are neglected. This method is most applicable to the analysis of the nighttime I-V curves. However when it is applied to daytime $\mathrm{I}-\mathrm{V}$ curves, it is recognized that the ion density may not be accurately determined and the electron temperature may be too high because additional ion current exists in both the ion saturation region and the transition region when the photoelectron current is not removed (Lebreton et al. 2006).

By the end of 2010 the DEMETER satellite mission was finished and had accumulated data for more than 6 years. The plasma parameters detected by the ISL have been used in many papers (Onishi et al. 2009; Jhuang et al. 2010; Kakinami et al. 2011; Li et al. 2011; Zhao et al. 2013). Kakinami et al. (2011) studied the daytime longitudinal structures of electron density and temperature in the topside ionosphere observed by the Hinotori and DEMETER satellites, which showed a similar longitudinal $\mathrm{N}_{\mathrm{e}}$ structure in the morning from July to October, and similar pronounced $\mathrm{N}_{\mathrm{e}}$ maxima in Southeast Asia, the Pacific Ocean and west of South America in the different solar flux conditions. In addition, Jhuang et al. (2010) found a middle latitude enhancement in DEMETER ISL data in the nighttime from September to April during 2005 - 2009, consistent with the ionospheric F2 region observation detected with ionosonde, incoherent scatter radar and the techniques for GPS total electron content (TEC) (Jhuang et al. 2010). Onishi et al. (2009) studied the MSTIDs using GPS TEC, which was also detected in the parallel plasma motion observation on DEMETER. Zhao et al. (2013) combined the $\mathrm{NmF} 2$ and $\mathrm{N}_{\mathrm{e}}$ data from ionosonde stations, COSMIC RO and DEMETER to study the east - west differences in the F-region over the Far East region, with some new features revealed for understanding the ionospheric longitude difference at mid-latitude. Kamogawa et al. (2011) and Kakinami et al. (2013) validated the DEMETER $\mathrm{N}_{e}$ and $\mathrm{T}_{\mathrm{e}}$ data using various satellites and found that the $T_{e}$ of DEMETER 
is larger by roughly $900 \mathrm{~K}$ than absolute $\mathrm{T}_{\mathrm{e}}$ values which may be due to probe contamination. During the daytime between 09:30 - 11:30 in the summer season the comparison exhibited that $\mathrm{N}_{\mathrm{e}}$ by DEMETER at latitude $10^{\circ}-30^{\circ}$ was the smallest among IRI, DE2, AEC, AED, Hinotori and FORMOSAT3, with at least half an order of magnitude difference. The ISL $\mathrm{N}_{\mathrm{e}}$ data by DEMETER was also compared with ground-based radar and $\mathrm{N}_{\mathrm{e}}$ at $670 \mathrm{~km}$ altitude by DEMETER was near to radar observation at similar height. They concluded that $\mathrm{N}_{\mathrm{e}}$ by DEMETER ISL observation was slightly small (Kakinami et al. 2013). It seems to the author that this evidence shows that the electron density observation with DEMETER seems acceptable when remarkable structures are studied such as the wave number-four longitudinal structure, the Weddell sea, MSTID, but $\mathrm{N}_{\mathrm{e}}$ may be a little smaller than its absolute value, especially in the local daytime.

\section{COMPARISON OF $\mathrm{N}_{\mathrm{e}}$ OBSERVED ON DEMETER AND PREDICTED BY IRI MODEL IN 2008}

Kakinami et al. (2011) pointed out that there were obvious seasonal variations in electron density with the smallest values in summer at the ionospheric height of DEMETER. In order to know the temporal-spatial behaviors in more detail for the yearly variations observed with DEMETER during the long period from July 2004 to December 2010, in the descending phase of the $23^{\text {rd }}$ solar cycle, the pictures of the global daytime $\mathrm{N}_{\mathrm{e}}$ distribution were drawn year by year in Fig. 1 with the data averaged in small bins of $4^{\circ} \times 1^{\circ}$ of geographical longitude and latitude, especially for the Northern (a)

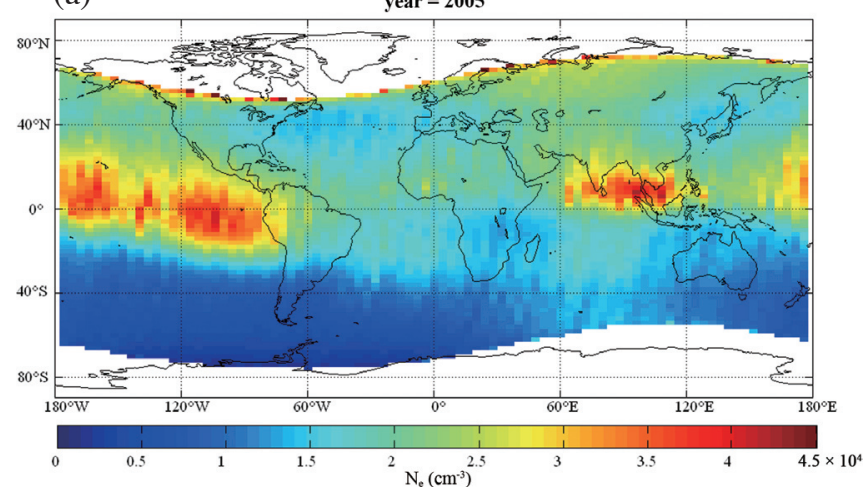

(c)

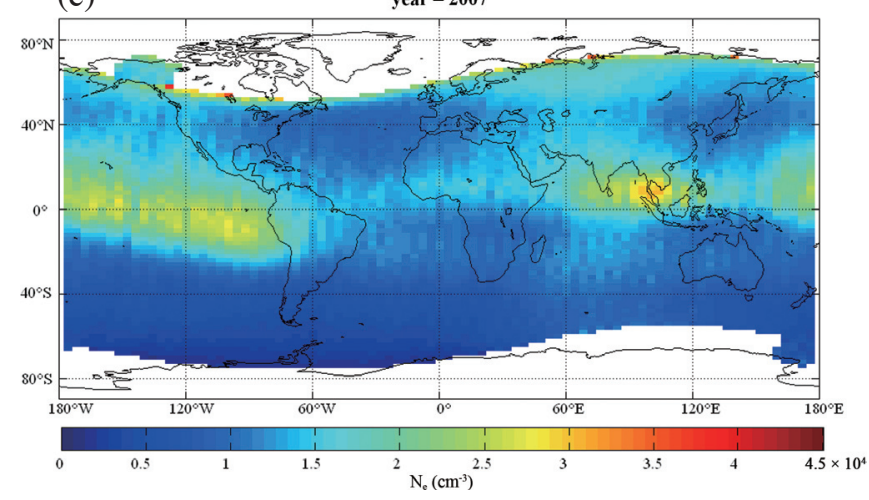

(e)

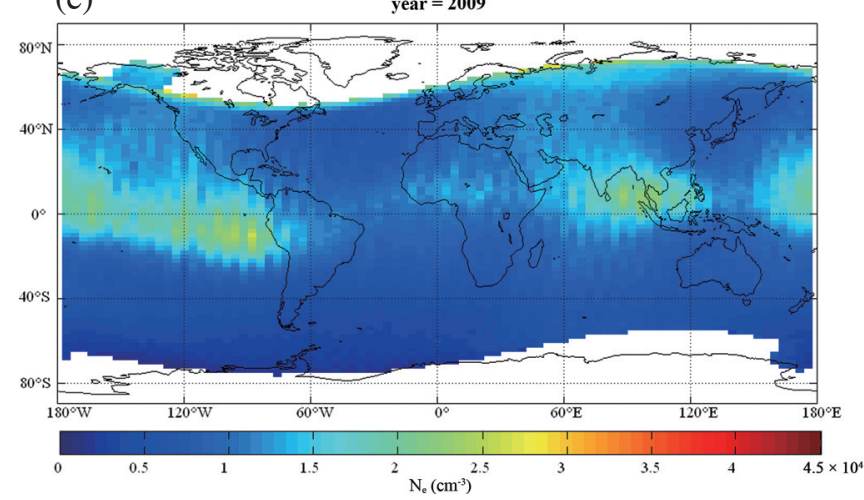

(b)

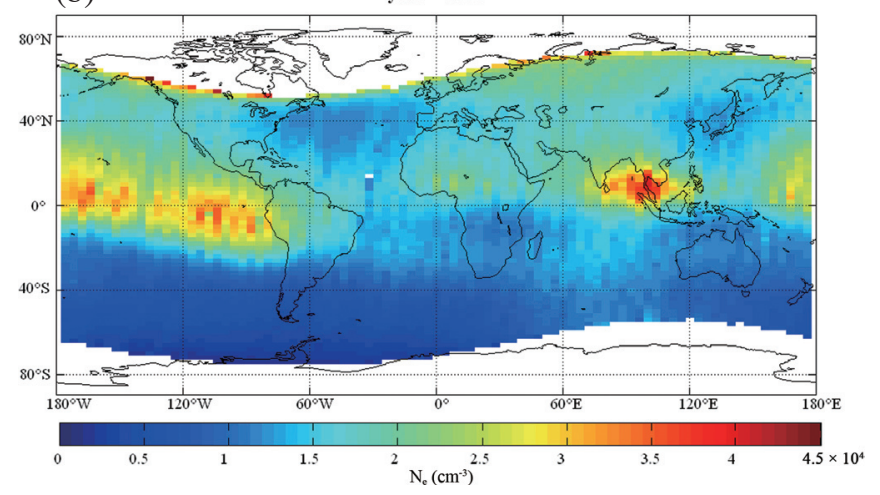

(d)

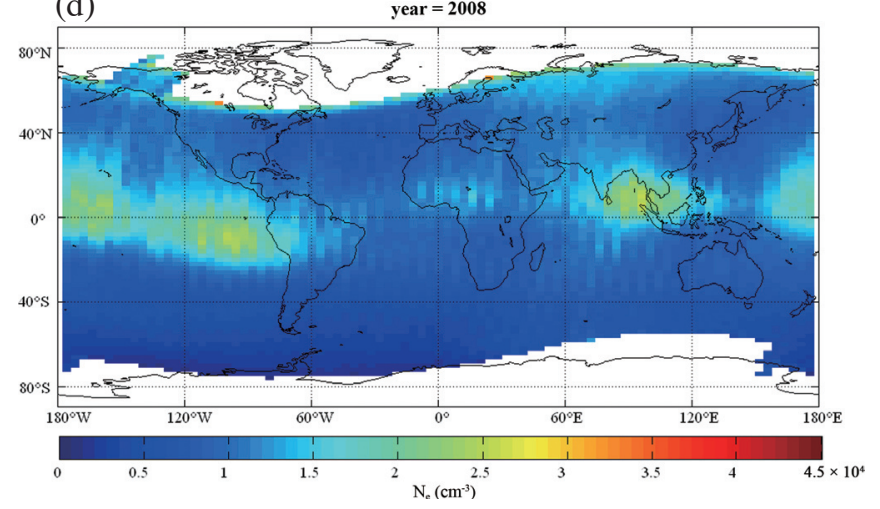

Fig. 1. $\mathrm{N}_{\mathrm{e}}$ distribution in June months (May - August) during 2005 - 2009 (a - e) around LT 09:00 - 11:30 based on DEMETER Langmuir probe data. 
Hemisphere summer season from May to August in the six years of 2005 - 2010 respectively. It can be seen that similar features of the global $\mathrm{N}_{\mathrm{e}}$ distribution are evident with crests around the magnetic equator (see the black lines there in Fig. 1) at June solstice and with crest values decreasing year by year until the lowest one in 2009 and recovering in 2010 , consistent with the observations by other satellites (Liu et al. 2009; Lühr and Xiong 2010). This behavior could be reasonably attributed to the influences of the solar cycle variations from $2005-2010$.

In order to obtain a quantitative estimate of the discrepancy in $\mathrm{N}_{\mathrm{e}}$ between the IRI model and DEMETER, the $\mathrm{N}_{\mathrm{e}}$ data selected from three seasons at equinox (March, April, September, October), June solstice (May to August) and December solstice (November, December, January, February) were examined respectively, by averaging the $\mathrm{N}_{\mathrm{e}}$ values in each bin of $2^{\circ} \times 1^{\circ}$ in longitude and latitude of the geomagnetic coordinate system, noted by $\overline{\mathrm{N}}_{\mathrm{e} \text {, DEMETER }}$. According to the DEMETER satellite operating mode the local times of descent orbits from north to south are from 11:30 - 09:00 LT and the ascent orbits from south to north are from 23:30 - 21:00 LT. The data were separated into two parts in local daytime and nighttime independently due to the large $\mathrm{N}_{\mathrm{e}}$ differences between them. On the other hand, the $\mathrm{N}_{\mathrm{e}}$ could be calculated strictly one by one with the IRI model according to the date,
LT and position with the original one from DEMETER, and the solar indices like Rz12, IG12 and F10.7 are input using the updated data file published on the http://irimodel.org/IRI2007/ website, denoted by $\mathrm{N}_{\mathrm{e}, \mathrm{IRI}}$. The seasonal averages of $\mathrm{N}_{\mathrm{e}}$ noted by $\overline{\mathrm{N}}_{\mathrm{e}, \text { IRI }}$ for each bin could then be performed by averaging all of the $\mathrm{N}_{\mathrm{e}}$ data in each bin during a specific season of a year. The relative discrepancy in $\mathrm{N}_{\mathrm{e}}$ between IRI-2007$\mathrm{N}_{\mathrm{e}}$ Quick and DEMETER, denoted by $\Delta \mathrm{N}_{\mathrm{e}}$ in each bin for the specific season, was given by the following formula:

$\Delta \mathrm{N}_{\mathrm{e}}=\frac{\overline{\mathrm{N}}_{\mathrm{e}, \text { IRI }}-\overline{\mathrm{N}}_{\mathrm{e}, \text { DEMETER }}}{\overline{\mathrm{N}}_{\mathrm{e}, \text { DEMETER }}} \times 100 \%$

Figure 2 shows the global $\mathrm{N}_{\mathrm{e}}$ distribution from DEMETER and IRI, as well as $\Delta \mathrm{N}_{\mathrm{e}}$ in the local daytime of equinoxes, June solstice and December solstice. It could be seen in Fig. 2 that significant differences appear between the $\mathrm{N}_{\mathrm{e}}$ spatial distributions in the daytime from the IRI model and DEMETER observations, especially in the equatorial area, where double peak zones appeared clearly at $\pm 10^{\circ}$ in the IRI model but only one crest zone around $0^{\circ}-10^{\circ}$ of geomagnetic latitude is shown by DEMETER observations. A large discrepancy of more than $630 \%$ is evident in the spatial distribution of $\Delta \mathrm{N}_{\mathrm{e}}$. Furthermore, if looked into in more detail, the values of $\mathrm{N}_{\mathrm{e}}$ in almost all of the points are overestimated
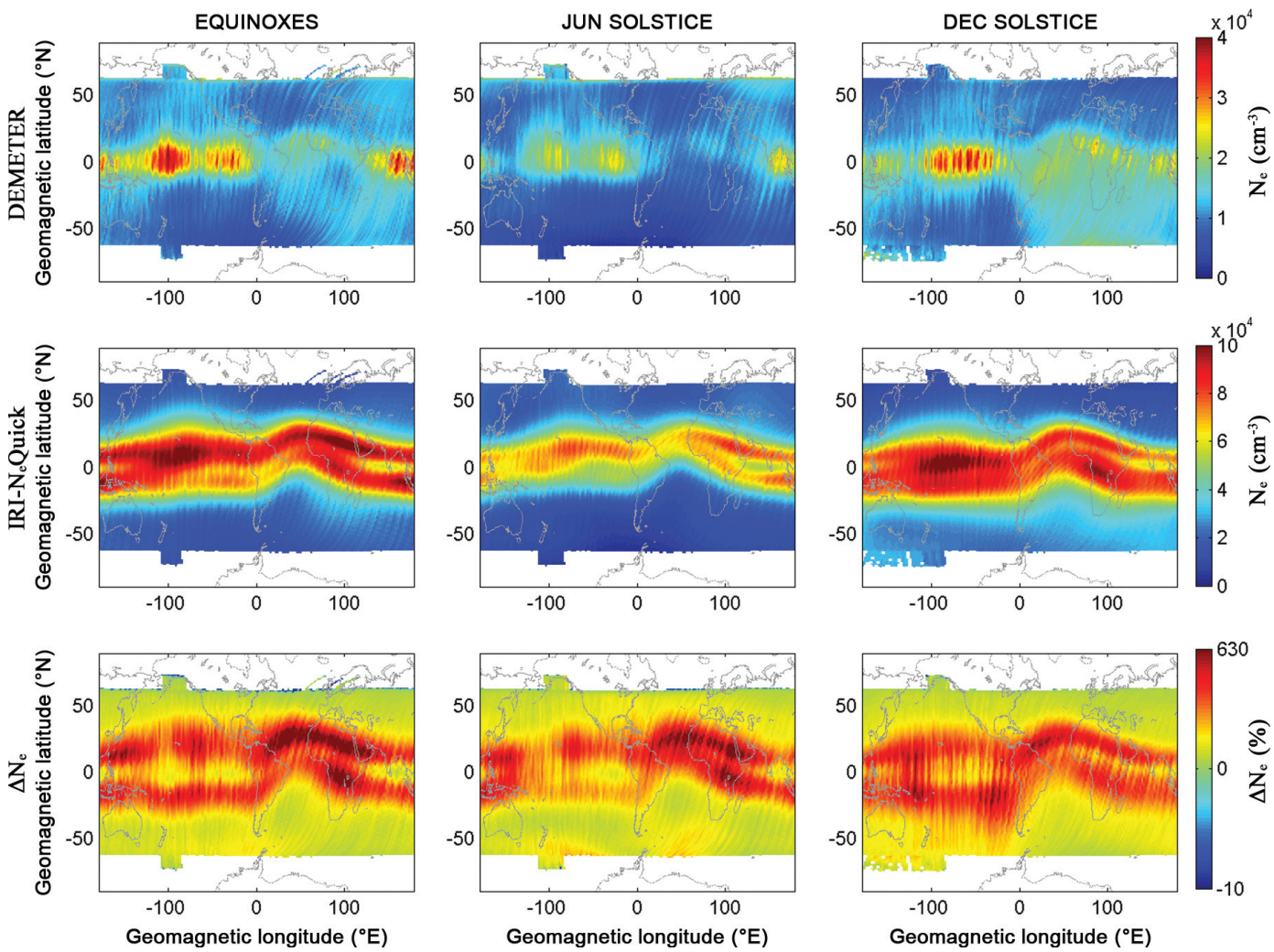

Fig. 2. Global $\mathrm{N}_{\mathrm{e}}$ distribution in the local daytime in three seasons from DEMETER (top panels from left to right: Equinoxes; June solstice; December solstice) and IRI-2007-NeQuick (middle panels from left to right: Equinoxes; June solstice; December solstice) in 2008 and relative deviation of $\mathrm{N}_{\mathrm{e}}$ in three seasons [bottom panels of $\Delta \mathrm{N}_{\mathrm{e}}(\%)$ from left to right: Equinoxes; June solstice; December solstice]. 
by the IRI model in the local daytime except for a few ones underestimated about $-10 \%$ at $65^{\circ} \mathrm{N}$ geomagnetic latitude, which is close to the highest latitude for DEMETER observations. At the region above $40^{\circ}$ of magnetic latitude, the $\mathrm{N}_{\mathrm{e}}$ values from the IRI model coincided with those from the DEMETER data.

Figure 3 shows the global $\mathrm{N}_{\mathrm{e}}$ distribution in the local nighttime, with some similar behaviors in both the DEMETER data and IRI models: peak values at the geomagnetic equator appeared in equinoxes and larger $\mathrm{N}_{\mathrm{e}}$ in the northern hemisphere in the June Solstice and higher $\mathrm{N}_{\mathrm{e}}$ in the south hemisphere in the December solstice.

It should be pointed out that, however, in 2008, the spatial pattern for $\Delta \mathrm{N}_{\mathrm{e}}$ exhibited large values which means that $\mathrm{N}_{\mathrm{e}}$ from the DEMETER data is obviously different from those from the IRI model at all three seasons of the year, in which $\mathrm{N}_{\mathrm{e}}$ was somewhere overestimated and somewhere underestimated, although the shapes of the global distribution of $\mathrm{N}_{\mathrm{e}}$ can certainly be similar in each season. The features in the local nighttime are summarized as follows: (1) $\mathrm{N}_{\mathrm{e}}$ values from the IRI model were higher in equatorial and high latitude areas for all seasons; (2) at equinox, $\mathrm{N}_{\mathrm{e}}$ is underestimated about $-70 \%$ at $20-40^{\circ}$ geomagnetic latitudes in both the southern and northern hemispheres; (3) in the June solstice $\mathrm{N}_{\mathrm{e}}$ is underestimated by about $-70 \%$ by the IRI model at middle latitudes in the southern hemisphere; (4) in the December solstice $\mathrm{N}_{\mathrm{e}}$ is underestimated by about $-70 \%$ at the middle latitudes in the northern hemisphere. Moreover, the wavelike longitudinal patterns of $\mathrm{N}_{\mathrm{e}}$ were evidently presented by DEMETER observations in the equinoxes and show seasonal features, as shown in the top three images of Fig. 3, which was also revealed by the COSMIC satellite in 2008 - 2009 (Liu et al. 2011b). It was not, however, evident in the IRI model (middle three images of Fig. 3).

\section{DISCUSSION}

By comparing the DEMETER and IRI models in 2008 it was found that (1), the IRI model overestimated the $\mathrm{N}_{\mathrm{e}}$ values over the equatorial area whether in the local daytime or nighttime, and (2), in the local daytime the spatial distribution of $\mathrm{N}_{\mathrm{e}}$ from the IRI model showed a double crest pattern, but only a single crest near the equator from the DEMETER observation. In previous papers, many people found the double-crest feature of $\mathrm{N}_{\mathrm{e}}$ at the equatorial area by satellite data, such as CHAMP at $490 \mathrm{~km}$ and GRACE at $456-310 \mathrm{~km}$ height at LT 8:00 - 12:00 just as that by the IRI model (Lühr and Xiong 2010). But in this paper $\mathrm{N}_{e}$ exhibits only one crest at the magnetic equator at LT 10:30 at $670 \mathrm{~km}$ altitude for DEMETER. To corroborate this
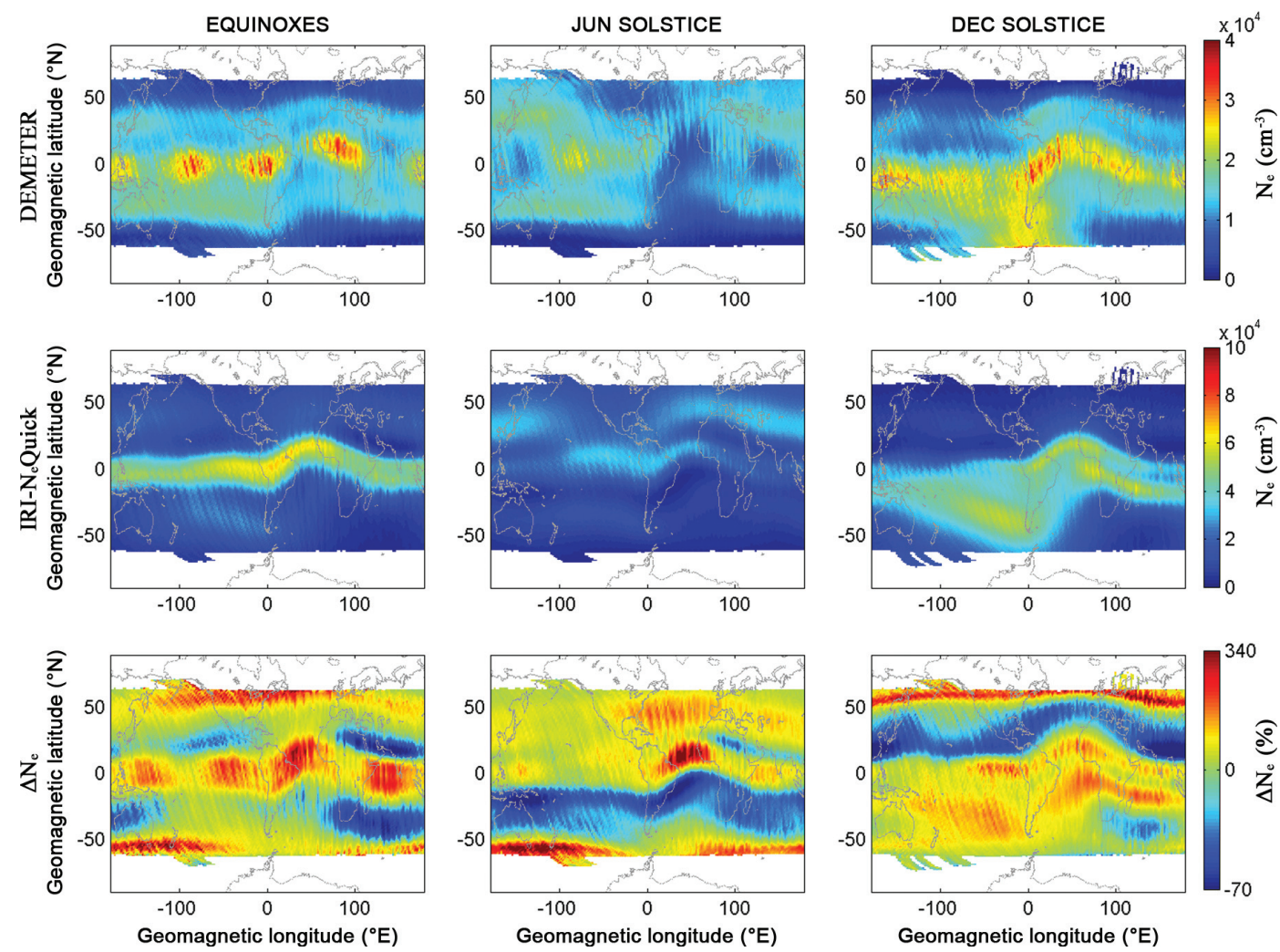

Fig. 3. Global $\mathrm{N}_{\mathrm{e}}$ distribution in the local nighttime in three seasons from DEMETER (top panels from left to right: Equinoxes; June solstice; December solstice) and IRI-2007- $\mathrm{N}_{\mathrm{e}}$ Quick (middle panels from left to right: Equinoxes; June solstice; December solstice) in 2008 and relative deviation of $\mathrm{N}_{\mathrm{e}}$ in three seasons [bottom panels of $\Delta \mathrm{N}_{\mathrm{e}}(\%)$ from left to right: Equinoxes; June solstice; December solstice]. 
feature, the Japan satellite Hinotori at about $600 \mathrm{~km}$ altitude is taken into account. As shown by Kakinami et al. (2011) for the Hinotori satellite, $\mathrm{N}_{\mathrm{e}}$ exhibited peak values around the equator at LT 09:00 - 11:00 during July to October in 1981, but two crests at $90^{\circ}-160^{\circ} \mathrm{E}$ in geographic longitude in the interval LT 13:00 - 15:00 during April - July in 1981 - 1982. In order to compare the $\mathrm{N}_{\mathrm{e}}$ values from Hinotori and DEMETER, four months' of data were collected in March, June, September, and December to represent the four seasons respectively. Data from the interval LT 08:00 - 11:00 were chosen from Hinotori to match up with the data near the local daytime of 10:30 for DEMETER. The Hinotori $\mathrm{N}_{\mathrm{e}}$ data exhibits a single crest in all four seasons (Fig. 4), and with the crest values and locations varying in different seasons and with the largest crest in December at $0^{\circ}-10^{\circ}$ geomagnetic latitude and the smallest one in June with relatively flat variation at $10^{\circ}-30^{\circ} \mathrm{N}$. This annual variation feature is quite similar to that shown in Fig. 2 from the DEMETER satellite. The results from the Hinotori satellite seem to verify that no double crests with valleys in the equatorial region might be reasonable at $600 \mathrm{~km}$ altitude at LT 09:00 - 11:00, so the IRI model should consider this characteristic in future prediction efforts. In addition, the $\mathrm{N}_{\mathrm{e}}$ data from the Dynamics Explorer 2 (DE-2) satellite of the USA was considered. The DE-2 was operated in the period July 1981 to February 1983 over the altitude range of $290-800 \mathrm{~km}$, and the $\mathrm{N}_{\mathrm{e}}$ data in March 1982 were selected in the time interval LT 10:00 - 12:00. Figure 5 shows its spatial variations with altitudes and latitudes, and reveals that there were two crests at $0^{\circ}-20^{\circ} \mathrm{S}$ and $20^{\circ}-40^{\circ} \mathrm{N}$ geographic latitude respectively when the altitude is lower than $500 \mathrm{~km}$. At altitudes above $500 \mathrm{~km}$ only one crest remained (although less data were observed) which was similar in the results from the Hinotori and DEMETER satellites. The merging of the anomaly crests into a single peak at high altitudes in the ionosphere is due to the fact that the electrons drifting down the magnetic

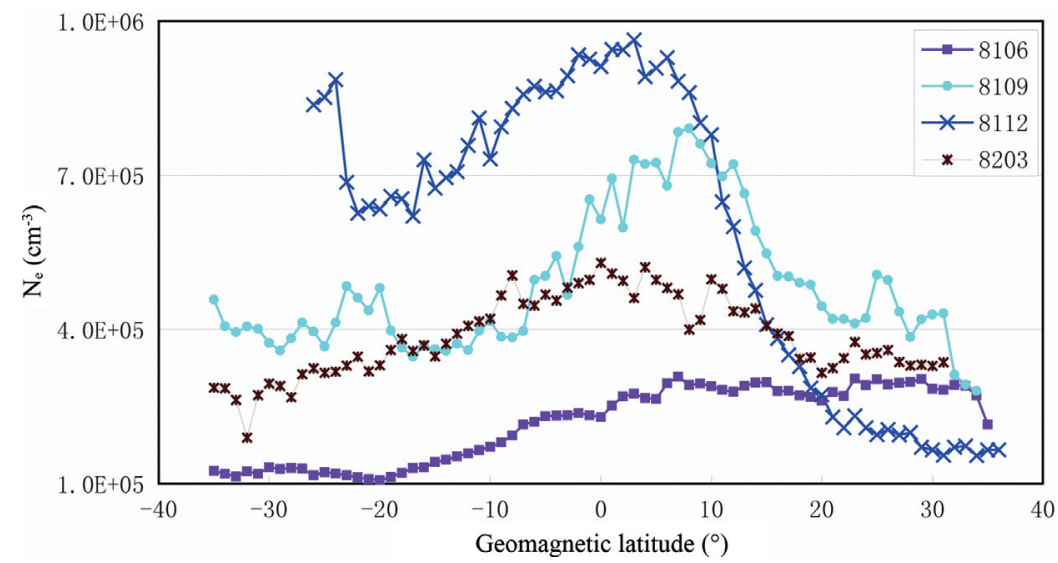

Fig. 4. $\mathrm{N}_{\mathrm{e}}$ recorded by the Hinotori satellite at $600 \mathrm{~km}$ altitude in four months at LT 08:00 - 11:00 in 1982 - 1983 (purple line with $\mathbf{m}$ : June in 1981; green line with $\bullet$ : September in 1981; blue line with $\times$ : December in 1981; brown line with *: March in 1982).

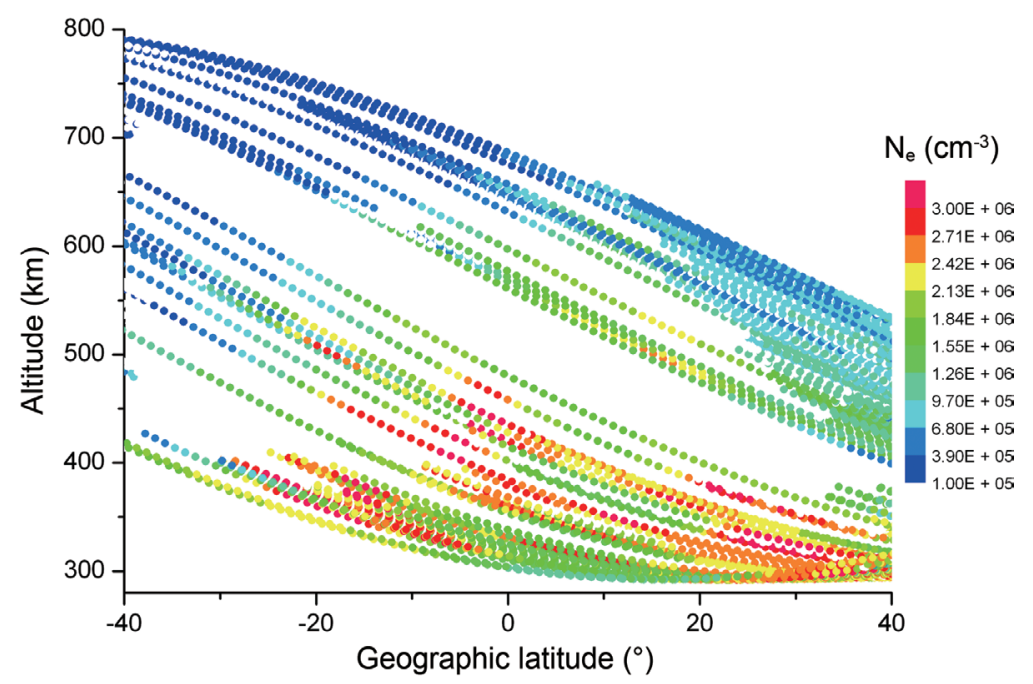

Fig. 5. $\mathrm{N}_{\mathrm{e}}$ recorded by the DE-2 satellite in March at LT 10:00 - 12:00 in 1982 [x-axis: geographic latitude; $y$-axis: altitude; color circle: $\mathrm{N}_{\mathrm{e}}\left(\mathrm{cm}^{-3}\right)$ ]. 
field lines are pushed up by the electro-jet induced electric field at the magnetic equator, which has been illustrated by topside sounder data (Eccles and King 1969). Based on the discussion mentioned above, the double-peak structure of the EIA at the bottom of the ionosphere should gradually evolve into a single peak at higher altitudes, as observed by multiple spacecraft. The single peak was observed at altitudes of $600 \mathrm{~km}$ from Hinotori during 09:00 - 11:00 LT and $670 \mathrm{~km}$ in the case of DEMETER around 10:30 LT. The single EIA peak has been detected as low as $500 \mathrm{~km}$ altitude from the FORMOSAT-3/COSMIC observation from 07:00 - 15:00 LT (Lin et al. 2007; Tulasi Ram et al. 2009).

On the other hand, three options in IRI-2007 to calculate the topside electron density could be considered, namely $\mathrm{N}_{\mathrm{e}}$ Quick, IRI-2001, IRI01-corr. Actually, $\mathrm{N}_{\mathrm{e}}$ Quick, the default option here, had been used for the previous section in this paper. Next we compare the other two options for the altitude variation investigation of the Equatorial Anomaly with the results from the $\mathrm{N}_{\mathrm{e}}$ Quick model. Figure 6 shows an example of three electron profiles at different altitudes from $-50^{\circ}$ to $50^{\circ}$ in geomagnetic latitude, along the geomagnetic longitude of $300^{\circ}$ at LT 10:30 on March 15 2008. It can be seen that, in the case of the $\mathrm{N}_{\mathrm{e}}$ Quick model, obvious double crests are presented between $-20^{\circ}$ to $20^{\circ}$ of geomagnetic latitude, even above the altitude of $700 \mathrm{~km}$, as shown in Fig. 6a. In the case of the IRI01-corr model double crests typically appear on two sides of the geomagnetic equator in Fig. 6b, with the values of $\mathrm{N}_{\mathrm{e}}$ larger than those in $\mathrm{N}_{\mathrm{e}}$ Quick. In the case of IRI-2001 model the south crest gradually disappears above the altitude of $600 \mathrm{~km}$, with only the northern crest remaining as shown in Fig. 6c. This behavior bears similar characteristics to the in-situ satellite observations mentioned above. Among those cases the maximum value of $\mathrm{N}_{\mathrm{e}}$ would be $0.8 \times 10^{11} \mathrm{~m}^{-3}$ in $\mathrm{N}_{\mathrm{e}}$ Quick, $1.4 \times 10^{11} \mathrm{~m}^{-3}$ in IRI01-corr and $1.8 \times 10^{11} \mathrm{~m}^{-3}$ in IRI-2001 at the same altitude of $700 \mathrm{~km}$. Figure 7 compares the IRI01-corr (Fig. 7a) and the IRI-2001 (Fig. 7b) models with DEMETER in 2008, in which the same color bar for $\Delta \mathrm{N}_{\mathrm{e}}$ as in Fig. 2 is used. The results in Fig. 7 show that the clear presence of double crests in the case of the IRI01-corr model in Fig. $7 \mathrm{a}$, and part $\Delta \mathrm{N}_{\mathrm{e}}$ exceeds $630 \%$ at equatorial areas. In Fig. $7 \mathrm{~b}$ mostly $\Delta \mathrm{N}_{\mathrm{e}}$ exceeds $630 \%$ around the equator, although double crests are not obvious in the IRI2001 model. So Figs. 6 and 7 both illustrate that the IRI-2001 model might well be suitable for describing the shape of the spatial distribution of $\mathrm{N}_{\mathrm{e}}$ at the altitude of DEMETER, but $\mathrm{N}_{\mathrm{e}}$ values in these two models are much larger than the real observations at the equatorial area. Instead, the $\mathrm{N}_{\mathrm{e}}$ Quick model used for representing the absolute $\mathrm{N}_{\mathrm{e}}$ seems to be a suitable one among three options of IRI 2007 because of its smallest crest in three options when the same altitude is chosen.

In contrast with the data from DEMETER in 2008, the minimum year of the $23^{\text {rd }}$ solar cycle, the data in 2005 , in the transition period of the descending branch of this cycle was also considered. Figure 8 shows the spatial distribution results for $\mathrm{N}_{\mathrm{e}}$ in three seasons of 2005 by DEMETER, IRI$\mathrm{N}_{\mathrm{e}}$ Quick, and their discrepancies in the local daytime. It can be seen that in both the DEMETER satellite data and in the IRI model, the $\mathrm{N}_{\mathrm{e}}$ values were larger than those in 2008 in the equatorial peak region, but the three images showing the discrepancy $\Delta \mathrm{N}_{\mathrm{e}}$ at the bottom of Fig. 8 are similar to those

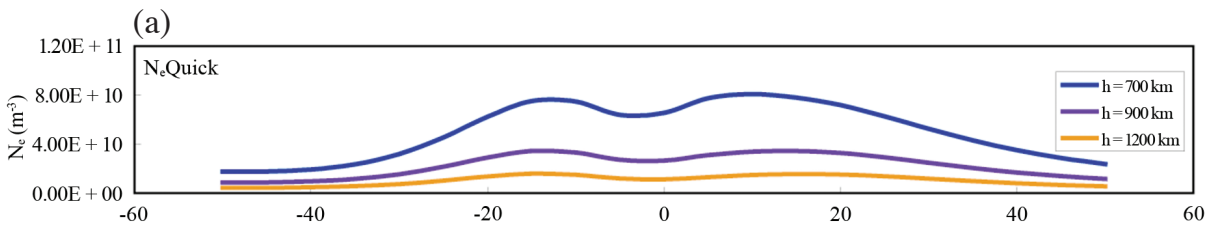

(b)

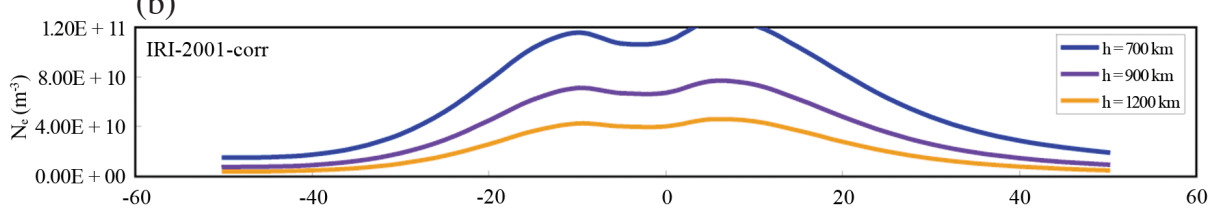

(c)

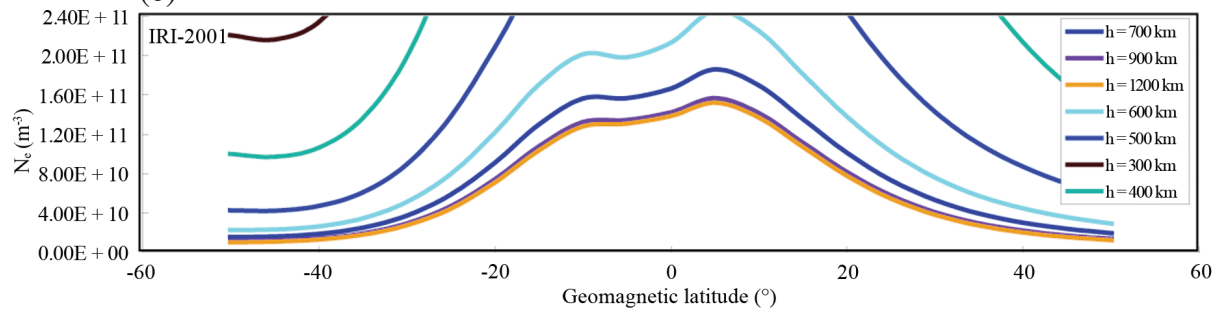

Fig. 6. $\mathrm{N}_{\mathrm{e}}$ profiles at different altitudes (deep blue: $700 \mathrm{~km}$; deep purple: $900 \mathrm{~km}$; yellow: $1200 \mathrm{~km}$ ) along geomagnetic latitude at geomagnetic longitude $300^{\circ}$ at LT 10:30 on March 152008 [(a) IRI-2007-N Quick; (b) IRI01-corr; (c) IRI-2001, also including 600 km (green line); 500 km (blue line); $400 \mathrm{~km}$ (deep green) and $300 \mathrm{~km}$ (brown line)]. 

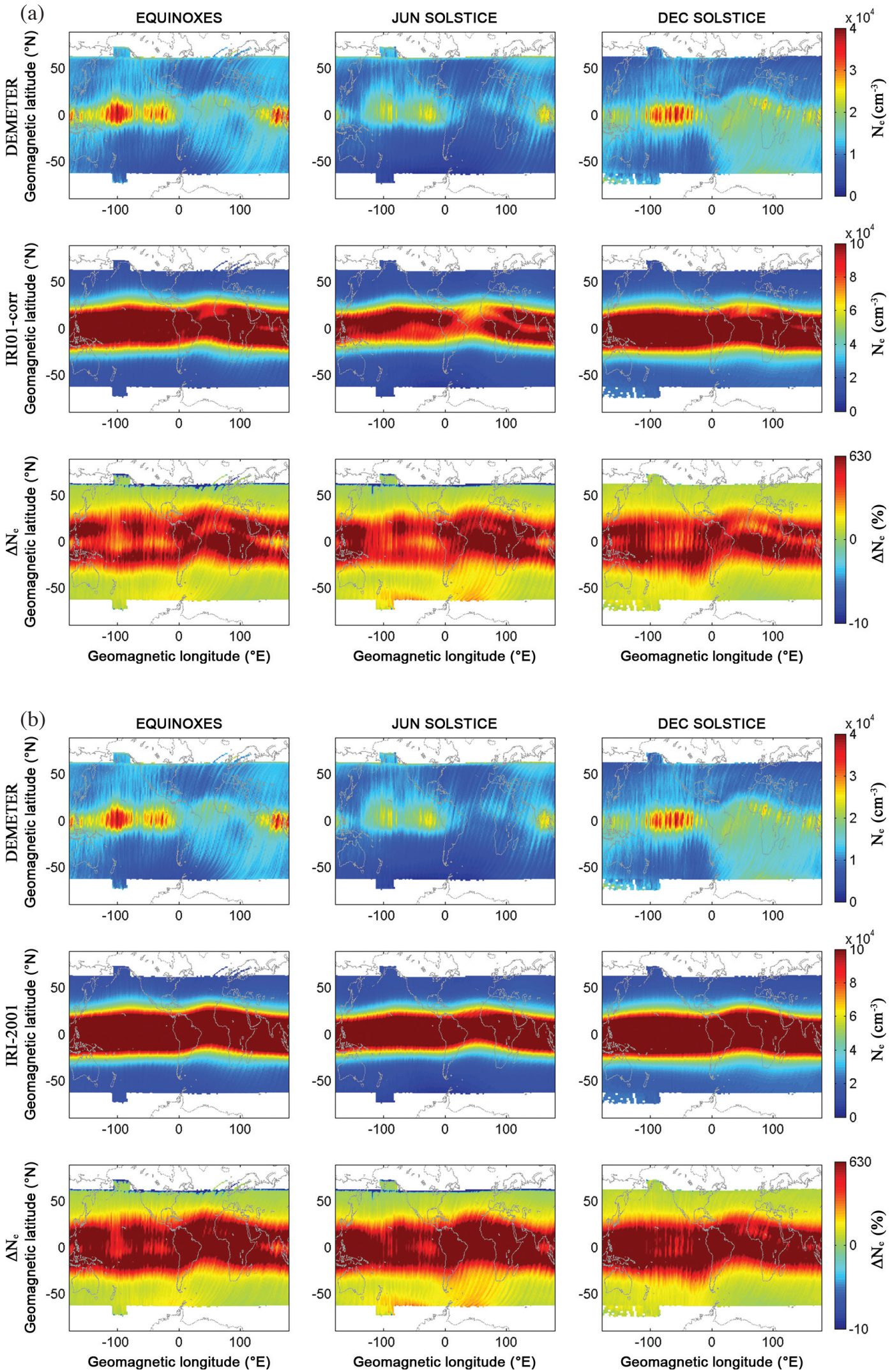

Fig. 7. Global $\mathrm{N}_{\mathrm{e}}$ distribution in the local daytime in three seasons from DEMETER (top panels from left to right: Equinoxes; June solstice; December solstice) and IRI model (middle panels of three seasons; (a) IRI01-corr; (b) IRI-2001) in 2008 and relative discrepancy of $\mathrm{N}_{\mathrm{e}}$ [bottom panels in $\Delta \mathrm{N}_{\mathrm{e}}(\%)$ in three seasons]. 

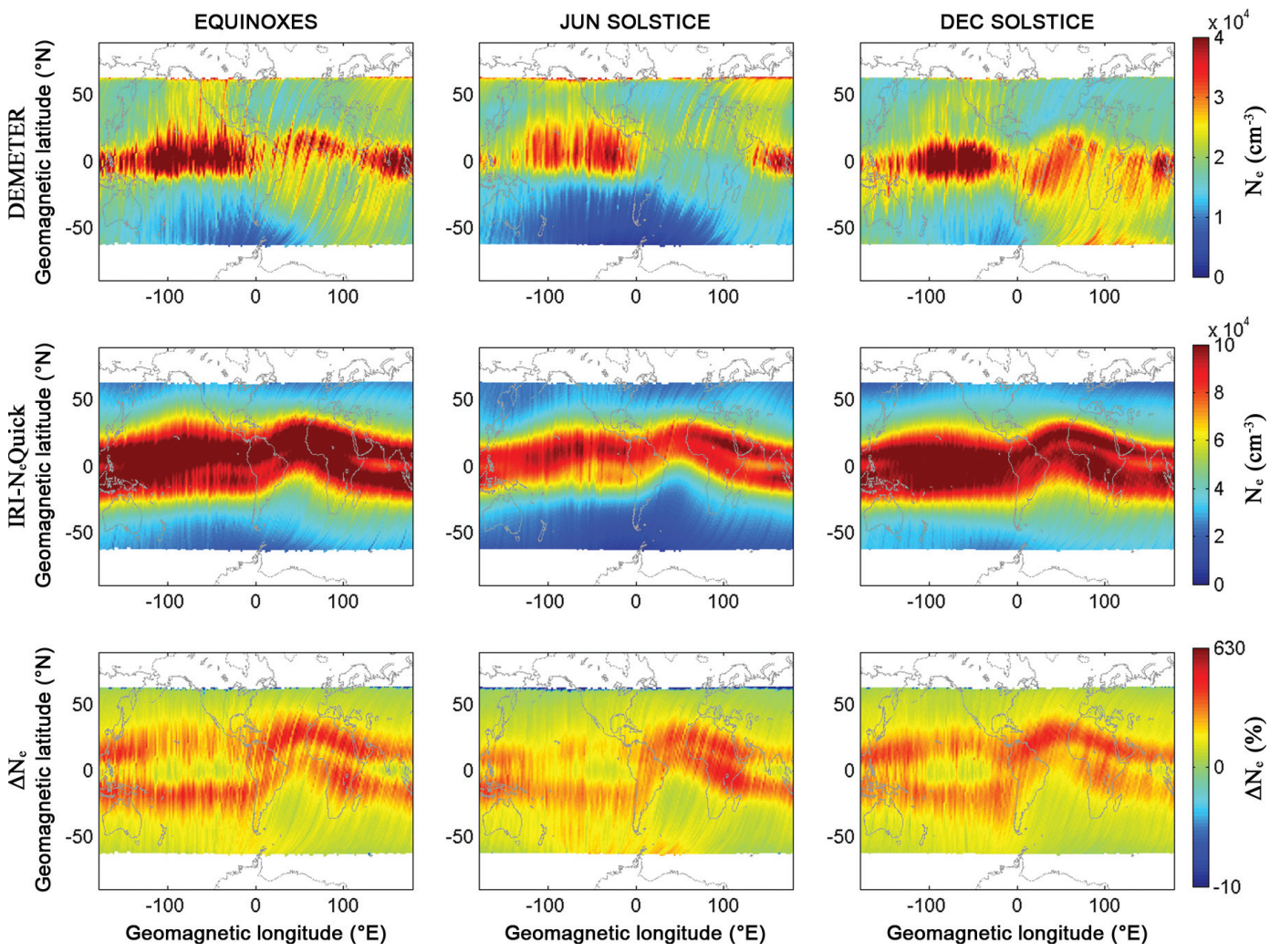

Fig. 8. Global $\mathrm{N}_{\mathrm{e}}$ distribution in the local daytime in three seasons from DEMETER (top panels from left to right: Equinoxes; June solstice; December solstice) and IRI-2007- $\mathrm{N}_{\mathrm{e}}$ Quick (middle panels in three seasons) in 2005 and relative discrepancy of $\mathrm{N}_{\mathrm{e}}$ in three seasons [bottom panels in $\Delta \mathrm{N}_{\mathrm{e}}(\%)$ in three seasons].

in Fig. 2 in 2008. Table 1 lists all of the average discrepancies $\Delta \mathrm{N}_{\mathrm{e}}$ in 2005 and 2008, it can be seen that in the local daytime $\Delta \mathrm{N}_{\mathrm{e}}$ was always bigger in 2008 than in 2005 and for all three options in the IRI model the largest difference occurred in IRI-2001. In local nighttime, $\Delta \mathrm{N}_{\mathrm{e}}$ was similar in the daytime and nighttime during 2005 and 2008 according to both IRI-2001 and IRI01-corr, but $\mathrm{N}_{\mathrm{e}}$ Quick showed smaller $\Delta \mathrm{N}_{\mathrm{e}}$ in 2008 than in 2005. This behavior of $\Delta \mathrm{N}_{\mathrm{e}}$ in the local nighttime illustrates that the $\mathrm{N}_{\mathrm{e}}$ values from DEMETER in the local nighttime were much more accurate than those in the local daytime. The results of $\Delta \mathrm{N}_{\mathrm{e}}$ in the local daytime reflect not only the data error from probe contamination (with the bigger $\Delta \mathrm{N}_{\mathrm{e}}$ than those in the local nighttime), but also demonstrate the overestimation of $\mathrm{N}_{\mathrm{e}}$ by IRI in 2008 with much larger discrepancies than those in 2005.

Based on theoretical analysis, the equatorial fountain effect is caused mainly by the upward movement due to $\overrightarrow{\mathrm{E}} \times \overrightarrow{\mathrm{B}}$, the northward and eastward drift by neutral wind (Lin et al. 2007 and references therein). If the neutral wind effect prevails the electron density concentrates at locations closer to the magnetic equator or to the southern/winter hemisphere. Otherwise, if the fountain effect is dominant, the EIA crest forms in a pole ward location (Lin et al. 2007; Tulasi Ram et al. 2009). At the topside ionosphere the DEMETER altitude the neutral wind effect will be prom- inent rather than the fountain feature in a solar minimum year. As for quick electron density reduction at the equatorial area and the big differences between DEMETER and IRI in 2008, Lühr and Xiong (2010) thought that the chemical and dynamic processes might change in the mesosphere and the lower ionosphere due to the decrease in thermospheric mass density (Emmert et al. 2010) during the deep minimum of the solar cycle from CHAMP and GRACE $\mathrm{N}_{\mathrm{e}}$ data. Simulation results implied that the decline in solar EUV during this period is the primary contributor to the upper atmospheric cooling (Chen et al. 2011). In contrast the greenhouse gases such as $\mathrm{CO}_{2}$ play only a secondary role in this unusual change (Solomon et al. 2010). Liu et al. (2007b) used $\mathrm{N}_{\mathrm{i}}$ data detected by the DMSP spacecraft to study the yearly variations in the top ionosphere at $840 \mathrm{~km}$ altitude and pointed out that the neutral oxygen $(\mathrm{O})$ density and the thermospheric neutral wind speeds should contribute to the annual asymmetry in the global $\mathrm{N}_{\mathrm{i}}$ distribution. At night the electron density production via the photoionization effects cease and the nitrogen $\left(\mathrm{N}_{2}\right)$ molecular density will play a more important role than $(\mathrm{O})$. The local nighttime distribution obtained by DEMETER, as shown in Fig. 3, reveals that when the solar zenith angle is inclined to the southern hemisphere (in Northern Hemisphere Winter), the $\mathrm{N}_{\mathrm{e}}$ was overestimated in the southern hemisphere and underestimated 
Table 1. $\Delta \mathrm{N}_{\mathrm{e}}(\%)$ from DEMETER and the IRI model in three seasons of both 2005 and 2008.

\begin{tabular}{|c|c|c|c|c|c|c|c|c|c|c|}
\hline \multirow{2}{*}{ Year } & \multirow{2}{*}{ LT } & \multicolumn{3}{|c|}{ IRI-N Quick } & \multicolumn{3}{|c|}{ IRI-2001 } & \multicolumn{3}{|c|}{ IRI01-corr } \\
\hline & & Equ. & Jun. & Dec. & Equ. & Jun. & Dec. & Equ. & Jun. & Dec. \\
\hline \multirow{2}{*}{2005} & daytime & 182.84 & 160.23 & 171.88 & 238.24 & 251.82 & 233.70 & 182.70 & 183.65 & 175.49 \\
\hline & nighttime & 79.83 & 50.28 & 67.68 & 183.97 & 165.15 & 169.69 & 97.52 & 81.19 & 87.51 \\
\hline \multirow{2}{*}{2008} & daytime & 226.61 & 189.56 & 226.92 & 357.41 & 355.56 & 355.59 & 289.32 & 270.24 & 290.12 \\
\hline & nighttime & 59.52 & 44.08 & 49.02 & 176.34 & 163.44 & 158.95 & 98.40 & 87.69 & 87.57 \\
\hline
\end{tabular}

in the northern middle latitudes, and vice versa. The dynamic process at middle latitude between the thermosphere and ionosphere should consider additional factors such as neutral gas density of $\left(\mathrm{N}_{2}\right)(\mathrm{O})$, and global thermospheric circulation effects (Bailey et al. 2000).

\section{CONCLUSION}

The comparison of global $\mathrm{N}_{\mathrm{e}}$ distribution features both from the DEMETER satellite at $670 \mathrm{~km}$ in the solar minimum year (2008) and from IRI 2007 was investigated in this paper with the following results.

(1) The spatial distribution of $\mathrm{N}_{\mathrm{e}}$ at LT 10:30 observed by DEMETER at the altitude of $670 \mathrm{~km}$ showed a single crest feature over the equatorial area which is different from that predicted from the $\mathrm{N}_{\mathrm{e}}$ Quick option in the IRI 2007 model, with the crest value from DEMETER largely overestimated by up to $600 \%$ by the model in different seasons of the satellite in terms of the formula-(1) for $\Delta \mathrm{N}_{\mathrm{e}}$. The same comparison for the year of 2005 gave similar results.

(2) Furthermore, three IRI-2007 model options were checked in the comparison with DEMETER observations. It could be seen that, among the three options considered, the IRI-2001 option shows a similar shape with single $\mathrm{N}_{\mathrm{e}}$ crest in the equatorial area to that from DEMETER at LT 10:30 at an altitude of $670 \mathrm{~km}$, but the smallest values of $\mathrm{N}_{\mathrm{e}}$ in the crest from the $\mathrm{N}_{\mathrm{e}}$ Quick option would be close to those from DEMETER. In general, the larger $\mathrm{N}_{\mathrm{e}}$ discrepancies in 2005 and 2008 predicted from any option demonstrate the error in the DEMETER Langmuir Probe data processing in the local daytime. The larger $\mathrm{N}_{\mathrm{e}}$ deviations in 2008 than 2005 still demonstrate the overestimation of $\mathrm{N}_{\mathrm{e}}$ in this minimum solar activity period.

(3) The data from other satellites such as CHAMP, Hinotori, and DE-2, operated at different altitudes imply that there might exist a kind of altitude effects i.e., the double crest due to the fountain effect over the equatorial area would gradually evolve into a single crest above $600 \mathrm{~km}$ from the bottom of the ionosphere, or to say the EIA would have not formed at LT 10:30 at the height of the DEMETER satellite. The calculation from the IRI 2007 model could also verify the conjecture for the existence of an altitude effect. It seems to the author that the appearance of a single crest in $\mathrm{N}_{\mathrm{e}}$ from DEMETER might be due to the fact that the operational altitude of the satellite is above the transition point for the altitude effects.

(4) The global distribution of $\mathrm{N}_{e}$ in the local nighttime showed quite similar behaviors both from DEMETER data and the IRI model. However, the spatial pattern for $\Delta \mathrm{N}_{\mathrm{e}}$ still showed that $\mathrm{N}_{\mathrm{e}}$ from DEMETER data was overestimated in the equatorial area. The model tended to underestimate in the nighttime winter hemisphere and overestimate in the summer hemisphere.

(5) In view of the big differences between the DEMETER satellite and the IRI model, especially in the equatorial area in the local daytime in 2005 and 2008, further study in the future is justified to improve the data processing technique in fitting the I-V curves and getting more accurate $\mathrm{N}_{\mathrm{e}}$ and $\mathrm{T}_{\mathrm{e}}$ data. It should be noted here that although the $\mathrm{N}_{\mathrm{e}}$ observed by DEMETER may be a little smaller than the absolute one in the local daytime. Structural features such as the single crest and the wave number four longitudinal structures along the equator cannot be doubted, which should be considered in continuous IRI improvement in a special period and at a certain altitude.

Acknowledgements The author greatly thanks the Anonymous Reviewers for their valuable comments, which greatly improved the manuscript. Prof. Zuo Xiao, Libo Liu, Earle Williams and Jiadong Qian gave good suggestions to polish the language and the content. We thank the DEMETER center for providing ISL data and the NASA website for access to other satellite data. This paper is supported by the National High-tech R\&D Program (863 Program: 2012AA121004).

\section{REFERENCES}

Araujo-Pradere, E. A., R. Redmon, M. Fedrizzi, R. Viereck, and T. J. Fuller-Rowell, 2011: Some characteristics of the ionospheric behavior during the Solar Cycle 2324 minimum. Sol. Phys., 274, 439-456, doi: 10.1007/ s11207-011-9728-3. [Link]

Bailey, G. J., Y. Z. Su, and K. I. Oyama, 2000: Yearly 
variations in the low-latitude topside ionosphere. Ann. Geophys., 18, 789-798, doi: 10.1007/s00585-000-07890 . [Link]

Bhuyan, P. K., M. Chamua, K. Bhuyan, P. Subrahmanyam, and S. C. Garg, 2003: Diurnal, seasonal and latitudinal variation of electron density in the topside F-region of the Indian zone ionosphere at solar minimum and comparison with the IRI. J. Atmos. Sol.-Terr. Phys., 65, 359368, doi: 10.1016/S1364-6826(02)00294-8. [Link]

Bilitza, D., 1992: International reference ionosphere (1990). Planet. Space Sci., 40, 544, doi: 10.1016/00320633(92)90174-M. [Link]

Bilitza, D., 2003: International reference ionosphere 2000: Examples of improvements and new features. Adv. Space Res., 31, 757-767, doi: 10.1016/S0273-1177(03)000206. [Link]

Bilitza, D., 2004: A correction for the IRI topside electron density model based on Alouette/ISIS topside sounder data. Adv. Space. Res., 33, 838-843, doi: 10.1016/j. asr.2003.07.009. [Link]

Bilitza, D. and B. W. Reinisch, 2008: International Reference Ionosphere 2007: Improvements and new parameters. Adv. Space. Res., 42, 599-609, doi: 10.1016/j. asr.2007.07.048. [Link]

Bilitza, D., S. A. Brown, M. Y. Wang, J. R. Souza, and P. A. Roddy, 2012: Measurements and IRI model predictions during the recent solar minimum. J. Atmos. Sol.-Terr. Phys., 86, 99-106, doi: 10.1016/j.jastp.2012.06.010. [Link]

Chen, Y., L. Liu, and W. Wan, 2011: Does the $F_{10.7}$ index correctly describe solar EUV flux during the deep solar minimum of 2007-2009? J. Geophys. Res., 116, A04304, doi: 10.1029/2010JA016301. [Link]

Cherniak, Iu. V., I. E. Zakharenkova, and D. A. Dzyubanov, 2013: Accuracy of IRI profiles of ionospheric density and temperatures derived from comparisons to Kharkov incoherent scatter radar measurements. Adv. Space Res., 51, 639-646, doi: 10.1016/j.asr.2011.12.022. [Link]

Cussac, T., M. A. Clair, P. Ultré-Guerard, F. Buisson, G. Lassalle-Balier, M. Ledu, C. Elisabelar, X. Passot, and N. Rey, 2006: The Demeter microsatellite and ground segment. Planet. Space Sci., 54, 413-427, doi: 10.1016/j.pss.2005.10.013. [Link]

Eccles, D. and J. W. King, 1969: A review of topside sounder studies of the equatorial ionosphere. P. IEEE, 57, 1012-1018, doi: 10.1109/PROC.1969.7145. [Link]

Emmert, J. T., J. L. Lean, and J. M. Picone, 2010: Record-low thermospheric density during the 2008 solar minimum. Geophys. Res. Lett., 37, L12102, doi: 10.1029/2010GL043671. [Link]

Ferguson, B. G. and L. F. McNamara, 1986: Calculation of $\mathrm{HF}$ absorption using the International Reference Ionosphere. J. Atmos. Terr. Phys., 48, 41-49, doi: 10.1016/0021-9169(86)90111-X. [Link]
Gibson, S. E., J. U. Kozyra, G. de Toma, B. A. Emery, T. Onsager, and B. J. Thompson, 2009: If the Sun is so quiet, why is the Earth ringing? A comparison of two solar minimum intervals. J. Geophys. Res., 114, A09105, doi: 10.1029/2009JA014342. [Link]

Heelis, R. A., W. R. Coley, A. G. Burrell, M. R. Hairston, G. D. Earle, M. D. Perdue, R. A. Power, L. L. Harmon, B. J. Holt, and C. R. Lippincott, 2009: Behavior of the $\mathrm{O}+/ \mathrm{H}+$ transition height during the extreme solar minimum of 2008. Geophys. Res. Lett., 36, L00C03, doi: 10.1029/2009GL038652. [Link]

Jhuang, H., J. G. Liu, and M. Parrot, 2010: The Midlatitude Electron Density Enhancement Observed by DEMETER. American Geophysical Union, Fall Meeting 2010, abstract \#AE21A-0255.Kakinami, Y., S. Watanabe, and K. I. Oyama, 2008: An empirical model of electron density in low latitude at $600 \mathrm{~km}$ obtained by Hinotori satellite. Adv. Space. Res., 41, 1495-1499, doi: 10.1016/j.asr.2007.09.031. [Link]

Kakinami, Y., S. Watanabe, and K. I. Oyama, 2008: An empirical model of electron density in low latitude at 600 km obtained by Hinotori satellite. Adv. Space Res., 41, 1495-1499, doi: 10.1016/j.asr.2007.09.031. [Link]

Kakinami, Y., C. H. Lin, J. Y. Liu, M. Kamogawa, S. Watanabe, and M. Parrot, 2011: Daytime longitudinal structures of electron density and temperature in the topside ionosphere observed by the Hinotori and DEMETER satellites. J. Geophys. Res., 116, A05316, doi: 10.1029/2010JA015632. [Link]

Kakinami, Y., M. Kamogawa, T. Onishi, K. Mochizuki, J. P. Lebreton, S. Watanabe, M. Y. Yamamoto, and T. Mogi, 2013: Validation of electron density and temperature observed by DEMETER. Adv. Space Res., 52, 1267-1273, doi: 10.1016/j.asr.2013.07.003. [Link]

Kamogawa, M., Y. Kakinami, K. Mochizuki, J. J. Berthelier, X. Wang, T. Onishi, J. Y. Liu, and T. Kodama, 2011: Validation of Electron Density and Temperature Measurement of the DEMETER Satellite in Comparison with Those of Various Satellites. $2^{\text {nd }}$ International DEMETER Workshop, Paris, France, October 10 - 12, 2011.

Klenzing, J., F. Simões, S. Ivanov, R. A. Heelis, D. Bilitza, R. Pfaff, and D. Rowland, 2011: Topside equatorial ionospheric density and composition during and after extreme solar minimum. J. Geophys. Res., 116, A12330, doi: 10.1029/2011JA017213. [Link]

Klenzing, J., F. Simões, S. Ivanov, D. Bilitza, R. A. Heelis, and D. Rowland, 2013: Performance of the IRI2007 model for equatorial topside ion density in the African sector for low and extremely low solar activity. Adv. Space Res., 52, 1780-1790, doi: 10.1016/j. asr.2012.09.030. [Link]

Lagoutte, D., J. Y. Brochot, D. de Carvalho, F. Elie, F. Harivelo, Y. Hobara, L. Madrias, M. Parrot, J. L. Pinçon, J. J. Berthelier, D. Peschard, E. Seran, M. Gangloff, J. A. 
Sauvaud, J. P. Lebreton, S. Stverak, P. Travnicek, J. Grygorczuk, J. Slominski, R. Wronowski, S. Barbier, P. Bernard, A. Gaboriaud, and J. M. Wallut, 2006: The DEMETER Science Mission Centre. Planet. Space Sci., 54, 428-440, doi: 10.1016/j.pss.2005.10.014. [Link]

Lebreton, J. P., S. Stverak, P. Travnicek, M. Maksimovic, D. Klinge, S. Merikallio, D. Lagoutte, B. Poirier, P. L. Blelly, Z. Kozacek, and M. Salaquarda, 2006: The ISL Langmuir probe experiment processing onboard DEMETER: Scientific objectives, description and first results. Planet. Space Sci., 54, 472-486, doi: 10.1016/j. pss.2005.10.017. [Link]

Lei, J., S. Syndergaard, A. G. Burns, S. C. Solomon, W. Wang, Z. Zeng, R. G. Roble, Q. Wu, Y. H. Kuo, J. M. Holt, S. R. Zhang, D. L. Hysell, F. S. Rodrigues, and C. H. Lin, 2007: Comparison of COSMIC ionospheric measurements with ground-based observations and model predictions: Preliminary results. J. Geophys. Res., 112, A07308, doi: 10.1029/2006JA012240. [Link]

Lei, J., J. P. Thayer, W. Wang, and R. L. McPherron, 2011: Impact of CIR storms on thermosphere density variability during the solar minimum of 2008. Sol. Phys., 274, 427-437, doi: 10.1007/s11207-010-9563-y. [Link]

Li, L Y., J. Y. Yang, J. B. Cao, L. Lu, Y. Wu, and D. M. Yang, 2011: Statistical backgrounds of topsideionospheric electron density and temperature and their variations during geomagnetic activity. Chin. J. Geophys., 54, 2437-2444, doi: 10.3969/j.issn.00015733.2011.10.001. [Link]

Lin, C. H., J. Y. Liu, T. W. Fang, P. Y. Chang, H. F. Tsai, C. H. Chen, and C. C. Hsiao, 2007: Motions of the equatorial ionization anomaly crests imaged by FORMOSAT-3/COSMIC. Geophys. Res. Lett., 34, L19101, doi: 10.1029/2007GL030741. [Link]

Liu, H., C. Stolle, M. Förster, and S. Watanabe, 2007a: Solar activity dependence of the electron density in the equatorial anomaly regions observed by CHAMP. J. Geophys. Res., 112, A11311, doi: 10.1029/2007JA012616. [Link]

Liu, L., B. Zhao, W. Wan, S. Venkartraman, M. L. Zhang, and X. Yue, 2007b: Yearly variations of global plasma densities in the topside ionosphere at middle and low latitudes. J. Geophys. Res., 112, A07303, doi: 10.1029/2007JA012283. [Link]

Liu, L., W. Wan, B. Ning, and M. L. Zhang, 2009: Climatology of the mean total electron content derived from GPS global ionospheric maps. J. Geophys. Res., 114, A06308, doi: 10.1029/2009JA014244. [Link]

Liu, L., Y. Chen, H. Le, V. I. Kurkin, N. M. Polekh, and C. C. Lee, 2011a: The ionosphere under extremely prolonged low solar activity. J. Geophys. Res., 116, A04320, doi: 10.1029/2010JA016296. [Link]

Liu, L., H. Le, Y. Chen, M. He, W. Wan, and X. Yue, 2011b: Features of the middle- and low-latitude ionosphere during solar minimum as revealed from COSMIC radio occultation measurements. J. Geophys. Res., 116, A09307, doi: 10.1029/2011JA016691. [Link]

Liu, L., W. Wan, Y. Chen, and H. Le, 2011c: Solar activity effects of the ionosphere: A brief review. Chin. Sci. Bull., 56, 1202-1211, doi: 10.1007/s11434-010-4226-9. [Link]

Liu, L., J. Yang, H. Le, Y. Chen, W. Wan, and C. C. Lee, 2012: Comparative study of the equatorial ionosphere over Jicamarca during recent two solar minima. J. Geophys. Res., 117, A01315, doi: 10.1029/2011JA017215. [Link]

Livingston, W. and M. Penn, 2009: Are sunspots different during this solar minimum? Eos, Trans., $A G U, \mathbf{9 0}$, 257-258, doi: 10.1029/2009EO300001. [Link]

Lühr, H. and C. Xiong, 2010: IRI-2007 model overestimates electron density during the $23 / 24$ solar minimum. Geophys. Res. Lett., 37, L23101, doi: 10.1029/ 2010GL045430. [Link]

Maltseva, O. A., O. S. Poltavsky, and A. S. Shlyupkin, 2007: The IRI model residual difference and the new method of N(h)-profile determination. Acta Geophys., 55, 441458, doi: 10.2478/s11600-007-0014-6. [Link]

Onishi, T., T. Tsugawa, Y. Otsuka, J. J. Berthelier, and J. P. Lebreton, 2009: First simultaneous observations of daytime MSTIDs over North America using GPS-TEC and DEMETER satellite data. Geophys. Res. Lett., 36, L11808, doi: 10.1029/2009GL038156. [Link]

Oyinloye, J. O., 1988: Equatorial HF radio wave absorption measurements and the IRI. J. Atmos. Terr. Phys., 50, 519-522, doi: 10.1016/0021-9169(88)90110-9. [Link]

Russell, C. T., J. G. Luhmann, and L. K. Jian, 2010: How unprecedented a solar minimum? Rev. Geophys., 48, RG2004, doi: 10.1029/2009RG000316. [Link]

Solomon, S. C., T. N. Woods, L. V. Didkovsky, J. T. Emmert, and L. Qian, 2010: Anomalously low solar extreme-ultraviolet irradiance and thermospheric density during solar minimum. Geophys. Res. Lett., 37, L16103, doi: 10.1029/2010GL044468. [Link]

Tulasi Ram, S., S. Y. Su, and C. H. Liu, 2009: FORMOSAT-3/COSMIC observations of seasonal and longitudinal variations of equatorial ionization anomaly and its interhemispheric asymmetry during the solar minimum period. J. Geophys. Res., 114, A06311, doi: 10.1029/2008JA013880. [Link]

Tulasi Ram, S., J. Lei, S. Y. Su, C. H. Liu, C. H. Lin, and W. S. Chen, 2010: Dayside ionospheric response to recurrent geomagnetic activity during the extreme solar minimum of 2008. Geophys. Res. Lett., 37, L02101, doi: 10.1029/2009GL041038. [Link]

Watanabe, S., K. I. Oyama, and M. A. Abdu, 1995: Computer simulation of electron and ion densities and temperatures in the equatorial $F$ region and comparison with Hinotori results. J. Geophys. Res., 100, 14581-14590, 
doi: 10.1029/95JA01356. [Link]

Zakharenkova, I. E., A. Krankowski, D. Bilitza, Iu. V. Cherniak, I. I. Shagimuratov, and R. Sieradzki, 2013: Comparative study of foF2 measurements with IRI2007 model predictions during extended solar minimum. Adv. Space Res., 51, 620-629, doi: 10.1016/j. asr.2011.11.015. [Link]

Zhao, B., M. Wang, Y. Wang, Z. Ren, X. Yue, J. Zhu, W. Wan, B. Ning, J. Liu, and B. Xiong, 2013: East-west differences in $F$-region electron density at midlatitude: Evidence from the Far East region. J. Geophys. Res., 118, 542-553, doi: 10.1029/2012JA018235. [Link] 